\title{
A Simulation-Based Workshop to Improve Dermatologists' Communication Skills: A Pilot for Continuing Medical Education
}

\author{
Lina Saeed - Isabelle M. Sanchez • Nina C. Botto • Charles N. Ellis • \\ Erik J. Stratman · Jennifer Thompson · Kanade Shinkai
}

Received: October 1, 2018 / Published online: November 17, 2018

(C) The Author(s) 2018

\begin{abstract}
Introduction: Communication skills influence the quality of health care and patient experience; both may affect provider reimbursement. There are few opportunities available for practicing physicians to receive direct feedback on communication in patient encounters. The purpose of this simulation-based patient encounter workshop was for dermatologists to practice and obtain feedback on their communication skills.
\end{abstract}

Lina Saeed and Isabelle M. Sanchez are equally contributed.

Enhanced digital features To view enhanced digital features for this article go to: https://doi.org/10.6084/ m9.figshare.7258679.

L. Saeed · I. M. Sanchez · N. C. Botto .

K. Shinkai $(\bowtie)$

Department of Dermatology, University of

California San Francisco, San Francisco, CA, USA

e-mail: Kanade.Shinkai@ucsf.edu

C. N. Ellis

Department of Dermatology, University of

Michigan Medical School, Ann Arbor, MI, USA

E. J. Stratman

Department of Dermatology, Marshfield Clinic,

Marshfield, WI, USA

J. Thompson

American Academy of Dermatology, Schaumburg,

IL, USA
Methods: In March 2016, dermatologists participated in a workshop with four simulated patient encounters. Cases were developed based on a prior needs assessment. Standardized patient educators evaluated participants' communication using the Master Interview Rating Scale and provided verbal feedback. Physicians rated the usefulness of the simulation and the feedback received through a survey upon workshop completion.

Results: Of the 170 physicians who registered, 103 participated in the simulation. The workshop was highly rated in meeting its three learning objectives (score of 4.5-4.6 out of a maximum score of 5). The lowest-rated communication skills were as follows: allowing the patient to share their narrative thread (3.1), summarizing the patient's history from the provider (3.8), and assessing patient understanding (3.8).

Conclusions: Participants reported that this communication workshop effectively satisfied its learning objectives. Opportunities to practice and improve communication skills as part of continuing medical education will benefit the clinical experience of patients and physicians alike, and the workshop may be formatted to serve physicians of other specialties. The lowestscoring communication areas identified in this study present an opportunity to develop a tailored curriculum for physician-patient communication in the future. 
Keywords: Communication; Continuing medical education (CME); Dermatology; Feedback; Objective structured clinical examination (OSCE); Simulation; Standardized patient

\section{INTRODUCTION}

Patient-centered communication is increasingly being recognized as an essential physician competency, and improvement of this skill is expected at all levels of training and practice [1]. Physician communication influences quality of care and improves patient outcomes, affecting physical and emotional health, patient understanding of medical issues, adherence to treatment regimens, and patient satisfaction with healthcare [2-4]. Effective communication is critical to the patient experience, which has become an important performance metric, contributing to incentive consideration in hospital and provider reimbursement as part of value-based purchasing programs $[5,6]$. Patient survey results now affect reimbursement, which are derived from the Hospital Consumer Assessment of Healthcare Providers and Systems (HCAHPS) and the Merit-Based Incentive Payment System (MIPS) [formerly known as the Physician Quality Reporting System (PQRS)], among others [6].

While effective communication is considered a vital skill, many physicians believe they have inadequate training [2, 7]. Physicians struggle with delivering bad news and disclosing medical errors, often using poor methods of communication with their patients [8]. Despite the emphasis on communication skills in current medical school curricula, practicing physicians rarely have opportunities to receive constructive feedback and coaching on communication [8-10]. Some communication-focused training workshops have been described in graduate medical education, including simulated patient encounters for surgery residents $[8,11]$. To address this practice gap, we developed an objective structured clinical examination (OSCE) for physicians to practice, be evaluated, and receive coaching on their communication skills in a simulation setting.

\section{METHODS}

A patient communication workshop was offered at the American Academy of Dermatology (AAD) annual meeting in March 2016 in Washington, D.C. Participants registered for the workshop and completed at least one of the four following clinical scenarios: medication counseling (isotretinoin), delivering bad news (melanoma diagnosis), agenda setting, and dealing with unmet expectations. The workshop content was developed based on a prior needs assessment indicating communication skills as a practice gap for dermatologists.

In a simulated clinic setting, dermatologists interacted with a standardized patient (SP), a trained actor who represents a patient by providing a scripted personal history, physical symptoms, emotional characteristics, and everyday concerns similar to what providers may encounter in a clinic [12]. The actor was a patient educator with expertise in assessing communication skills and providing feedback and coaching.

At each station, participants were instructed to take a history and counsel the patient. The workshop participants were given necessary clinical information for each case, which included patient name, age, vital signs, medication list, and the chief complaint. After a 20-min encounter, the SP provided a detailed communication evaluation, coaching, and structured feedback to the participant using a standardized checklist. The SPs scored participants using an abbreviated version of the Master Interview Rating Scale (MIRS), a validated instrument to assess communication skills [13]. Participants evaluated their experience through a survey reporting whether the workshop met its learning objectives and rated the value of their simulation experience, scoring both on a 5 -point Likert response scale. Additionally, the participants listed barriers to effective communication that they may face in actual clinical practice.

All workshop content was approved by the AAD Scientific Assembly Committee. The programmatic evaluation of the workshop was 
granted exemption status by the UCSF Committee on Human Subjects Research.

\section{RESULTS}

Of the 170 dermatologists who registered, 103 participated in the workshop. There were 34, 29, 21, and 19 dermatologists who completed the managing expectations, agenda-setting, medication counseling, and delivering bad news scenarios, respectively. Most participants were new clinicians, senior clinicians, or fellows.

The average (mean) reported workshop learning objective achievement score was between 4.5 and 4.6 out of a maximum score of 5 (Table 1). The average (mean) communication score, as determined by the SP-rated abbreviated MIRS, was 3.1-4.8 out of a maximum score of 5 (Table 2). Participants' lowest-rated communication skills were identified as follows: allowing the patient to share their narrative thread (3.1), summarizing the patient's history from the provider (3.8), and assessing patient understanding (3.8). The most common barriers reported in clinical practice were lack of resources, administrative support, and time available in clinical practice to assess and counsel patients.

Table 1 Participant ratings of the workshop learning objectives

\begin{tabular}{|c|c|c|}
\hline \multirow[t]{2}{*}{ Learning objectives } & \multicolumn{2}{|l|}{ Scores ${ }^{\mathrm{a}}$} \\
\hline & Range & Mean \\
\hline $\begin{array}{l}\text { 1. Describe personal reflections after the } \\
\text { encounter and identify areas for } \\
\text { individualized improvement }\end{array}$ & $4.4-4.8$ & 4.5 \\
\hline $\begin{array}{l}\text { 2. Practice communication skills in a } \\
\text { realistic simulated clinical scenario }\end{array}$ & $4.3-5.0$ & 4.6 \\
\hline 3. Receive feedback on communication & $4.1-4.9$ & 4.5 \\
\hline
\end{tabular}

${ }^{a}$ Ratings based on a 5-point Likert scale: (1) not at all successful at achieving learning objectives; (2) not successful at achieving learning objectives; (3) neither successful nor unsuccessful at achieving learning objectives; (4) successful at achieving learning objectives; (5) greatly successful at achieving learning objectives
Table 2 Communication scores achieved by participants

\begin{tabular}{lll}
\hline MIRS question & $\begin{array}{l}\text { Range of } \\
\text { scores }^{\mathbf{a}}\end{array}$ & Mean \\
\hline 1. Opening/introduction & $4.2-4.9$ & 4.6 \\
2. Narrative thread & $3.6-4.4$ & $3.8^{\mathrm{b}}$ \\
3. Nonverbal facilitation & $4.6-5.0$ & 4.8 \\
4. Pace of interview & $4.5-4.7$ & 4.7 \\
5. Summarization and verification & $2.8-3.5$ & $3.1^{\mathrm{b}}$ \\
6. Encouraging questions & $3.3-5.0$ & 4.4 \\
7. (Avoiding) use of jargon & $4.3-4.8$ & 4.6 \\
8. Empathy & $3.3-4.2$ & 3.9 \\
9. Achieve a shared plan & $4.1-4.8$ & 4.6 \\
10. Patient education and & $3.4-4.3$ & $3.8^{\mathrm{b}}$ \\
\multicolumn{1}{c}{ understanding } & & \\
\hline
\end{tabular}

MIRS Master Interview Rating Scale (abbreviated version $)^{6}$

${ }^{a}$ MIRS scoring rubric based on a 5-point scale, where a maximum score of 5 indicates "excellent." Example of ratings (question 1): score of 1: "The interviewer fails to introduce himself, clarify his role, and inquire how to address patient;" score of 3: "The interviewer introduces himself, clarifies his roles, or inquires how to address patient but does not achieve all tasks;" score of 5: "The interviewer introduces himself, clarifies his roles, and inquires how to address patient"

b Identified areas of communication improvement, determined by the three lowest average MIRS scores

\section{DISCUSSION}

We developed an educational workshop with the goal to strengthen the communication skills of practicing dermatologists using SP simulation. Physicians found this OSCE workshop helpful for practice and feedback, uniformly rating that the workshop met its learning objectives. The aspects of physician-patient communication identified as potential areas for improvement were derived from the lowest average scores reported in this workshop. These identified areas included (1) the extent that the participant allowed the SP to share their narrative (e.g., minimizing interruptions to the 
patient narrative and eliciting patients' beliefs about their illness), (2) how well the physician summarized the history that was obtained from the SP (e.g., active listening), and (3) the assessment of patient understanding (e.g., confirming patient understanding by asking patients to restate their understanding of the disease and treatment plan). These areas present an opportunity to develop a curriculum to improve these specific communication skills.

OSCE workshops are relatively new components of continuing medical education, although this method has been integrated into medical school training for years [3, 14-16]. Examples of OSCE workshops for practicing physicians in the literature are limited. There are few articles that identify the use of OSCEs in training surgical residents and emergency medicine residents, and there are two communication-specific OSCEs among primary care residents [7, 8, 11, 17]. Among practicing physicians, there are several identified publications that report the use of OSCEs to enhance communication skills [10, 18-20]. OSCEs have been regularly integrated into the curriculum of medical students and among practicing pharmacists and veterinarians, but there are minimal publications that evaluate this education [21-24]. OSCE workshops have recently been implemented at continuing medical education conferences and are increasingly being used to refresh and refine procedural clinical skills among practitioners [25-27].

Although these scenarios were specific to dermatology, such as delivering the bad news of a skin cancer diagnosis and prioritizing multiple skin or hair complaints, similar situations are encountered within primary care, and these cases can be easily adapted to other specialties. We hope that our workshop may serve as a model to support efforts to increase the utilization of OSCE workshops for communication skills practice in continuing medical education in all specialties in the future.

This OSCE format could also be utilized for competency assessment for trainee coaching and assessment [28]. This curriculum may also be expanded to address additional continuing medical educational needs such as interprofessional communication skills, including giving and receiving feedback. We are developing additional simulation exercises for educators, including OSCE workshops for teaching procedural skills in dermatology.

In considering the Kirkpatrick hierarchy of objectively evaluating medical education interventions, the baseline of success is dependent upon the reactions and engagement of the participants, which our workshop adequately addresses [29]. In the future, we will address more advanced Kirkpatrick measures of workshop success, including improved patient satisfaction or treatment outcomes based on physician-patient communication skills.

Enhancing communication skills will allow physicians to meet new metrics and incentives for reimbursement that are tethered to patient satisfaction scores but, more importantly, it may also effectively strengthen the patient-physician relationship during clinical practice [30]. Enriching relationships between patients and providers may contribute to improved physician well-being and mitigate physician burnout $[2,6]$.

Although this educational workshop successfully demonstrated the feasibility of using this type of intervention in dermatology continuing education to optimize learning, it may not accurately reflect real-world experiences. Some participants found it useful to practice these skills, but noted that the cost, time constraints, and lack of administrative support hinder the implementation of some communication skills in clinical practice. For example, the length of the simulated encounter exceeds the time typically available for counseling patients in many clinical environments. Participants also commented that the absence of common communication barriers, such as a computer in the exam room, made the simulation less realistic. Shorter encounter times and the incorporation of electronic medical records could ensure a more high-fidelity simulation experience in future workshops. Additionally, the value of this formative coaching should be studied longitudinally to determine the impact of the workshop on participants' patient satisfaction scores or other metrics. In the future, we will incorporate these improvements to the OSCE communication workshops for 
continuing medical education and will continue to study this work in greater detail, as has been recommended by Wilbur et al. [27].

\section{CONCLUSIONS}

Overall, the participants found this OSCE simulation workshop to be effective and helpful. The attendees uniformly rated that the workshop met its prespecified learning objectives. We identified specific communication skills that require improvement amongst practicing dermatologists. Additionally, we will incorporate participant feedback on how to maximize more realistic patient encounters in the future. Developing highfidelity simulation-based programs that allow dermatologists to practice and receive constructive feedback on their communication skills may be a valuable addition to continuing medical education, and may in turn effectively help to improve the well-being of both patients and physicians.

\section{ACKNOWLEDGEMENTS}

We thank the participants of the study.

Funding. There were no funding sources for this work. The article processing charges were funded by the authors. This publication made possible in part by support from the UCSF Open Access Publishing Fund.

Authorship. All named authors meet the International Committee of Medical Journal Editors (ICMJE) criteria for authorship for this manuscript, take responsibility for the integrity of the work as a whole, and have given final approval for the version to be published.

Disclosures. Lina Saeed, Isabelle M. Sanchez, Nina C. Botto, Charles N. Ellis, Erik J. Stratman, Jennifer Thompson and Kanade Shinkai have nothing to disclose.

Compliance with Ethics Guidelines. The programmatic evaluation of the workshop was granted exemption status by the UCSF Committee on Human Subjects Research. All workshop content was approved by the AAD Scientific Assembly Committee.

Data Availability. The datasets obtained and/or analyzed during the current study are available from the corresponding author on reasonable request.

Open Access. This article is distributed under the terms of the Creative Commons Attribution-NonCommercial 4.0 International License (http://creativecommons.org/licenses/ by-nc/4.0/), which permits any noncommercial use, distribution, and reproduction in any medium, provided you give appropriate credit to the original author(s) and the source, provide a link to the Creative Commons license, and indicate if changes were made.

\section{REFERENCES}

1. Fletcher I, McCallum R, Peters S. Attachment styles and clinical communication performance in trainee doctors. Patient Educ Couns. 2016;99(11):1852-7.

2. Maguire $P$, Pitceathly C. Managing the difficult consultation. Clin Med (Lond, Engl). 2003;3(6):532-7.

3. Setyonugroho W, Kennedy KM, Kropmans TJ. Reliability and validity of OSCE checklists used to assess the communication skills of undergraduate medical students: a systematic review. Patient Educ Couns. 2015;98:1482-91.

4. Stewart MA. Effective physician-patient communication and health outcomes: a review. CMAJ. 1995;152(9):1423-33.

5. Chee TT, Ryan AM, Wasfy JH, Borden WB. Current state of value-based purchasing programs. Circulation. 2016;133(22):2197-205.

6. Mehta SJ. Patient satisfaction reporting and its implications for patient care. AMA J Ethics. 2015;17(7):616-21.

7. Chumpitazi CE, Rees CA, Chumpitazi BP, Hsu DC, Doughty CB, Lorin MI. Creation and assessment of a bad news delivery simulation curriculum for pediatric emergency medicine fellows. Cureus. 2016;8(5):e595.

8. Branson CF, Chipman JG. Improving surgical residents' communication in disclosing complications: a qualitative analysis of simulated physician and 
patient surrogate conversations. Am J Surg. 2018;215(2):331-5.

9. Rotthoff T, Baehring T, David DM, et al. The value of training in communication skills for continuing medical education. Patient Educ Couns. 2011;84(2):170-5.

10. Laidlaw TS, Kaufman DM, Sargeant J, MacLeod H, Blake K, Simpson D. What makes a physician an exemplary communicator with patients? Patient Educ Couns. 2007;68(2):153-60.

11. Sudan R, Lynch TG, Risucci DA, Blair PG, Sachdeva AK. American College of Surgeons Resident Objective Structured Clinical Examination: a national program to assess clinical readiness of entering postgraduate year 1 surgery residents. Ann Surg. 2014;260(1):65-71.

12. UCSF. Become a standardized patient. UCSF Medical Education. http://meded.ucsf.edu/simulation/ become-standardized-patient. Accessed 28 Feb 2018.

13. Pfeiffer CA. The Master Interview Rating Scale (MIRS): an instrument for faculty, students, and standardized patients to use for teaching and evaluation. 2013. https://icollaborative.aamc.org/resource/835/. Accessed 28 Feb 2018.

14. Goodyear HM. Problem based learning in a junior doctor teaching programme. Arch Dis Child. 2005;90(3):275-8.

15. Wagner JA, Pfeiffer CA, Harrington KL. Evaluation of online instruction to improve medical and dental students' communication and counseling skills. Eval Health Prof. 2011;34(3):383-97.

16. Ludwig A, Lee R, Parish S, Raff A. Four-station group observed structured clinical encounter for formative assessment of communication skills for internal medicine clerks. MedEdPORTAL. 2016;12:10444.

17. Meltzer EC, Shi Z, Suppes A, et al. Improving communication with surrogate decision-makers: a pilot initiative. J Grad Med Educ. 2017;9(4):461-6.

18. Mehdizadeh L, Sturrock A, Dacre J. Are the General Medical Council's tests of competence fair to long standing doctors? A retrospective cohort study. BMC Med Educ. 2015;15:80.

19. Pascual-Ramos V, Flores-Alvarado DE, Portela-Hernandez $\mathrm{M}$, et al. Communication skills in candidates for accreditation in rheumatology are correlated with candidate's performance in the objective structured clinical examination. Reumatol Clin. 2017;14(6):317-82.
20. Antoun J, Romani M, Saab B. Disclosure of medical error-objective structured clinical examination (OSCE). MedEdPORTAL. 2012;8:9226.

21. College of Veterinary Medicine and Biomedical Sciences-Colorado State University. Veterinary communication for professional excellence: Frank Communication Workshop Series. 2016. http://csucvmbs.colostate.edu/academics/clinsci/veterinarycommunication/Pages/frank-workshops.aspx. Accessed 24 Apr 2018.

22. American Veterinary Medical Association. Meetings and CE Calendar: Frank 2.0 Communication Workshop for Continuing Education. 2017; https:// www.avma.org/events/calendar/pages/event. aspx?EventID=36546. Accessed 24 Apr 2018.

23. International Conference on Communication in Veterinary Medicine. Workshop Cohesive Debriefing from the Clinical Communication Program Coach of Washington State University's Clinical Simulation Center. 2018. https://www. eiseverywhere.com/ehome/iccvm2018/688698/. Accessed 24 Apr 2018.

24. Urteaga EM, Attridge RL, Tovar JM, Witte AP. Evaluation of clinical and communication skills of pharmacy students and pharmacists with an objective structured clinical examination. Am J Pharm Educ. 2015;79(8):122.

25. Zabar S, Hanley K, Stevens DL, et al. Can interactive skills-based seminars with standardized patients enhance clinicians' prevention skills? Measuring the impact of a CME program. Patient Educ Couns. 2010;80(2):248-52.

26. Colwell J. Taking communication skills seriously: formal training can improve patient satisfaction, physician burnout. 2016. https://acphospitalist. org/archives/2016/10/communication-training. htm. Accessed 24 Apr 2018.

27. Wilbur K, Elmubark A, Shabana S. Systematic review of standardized patient use in continuing medical education. J Contin Educ Health Prof. 2018;38(1):3-10.

28. Cauthon KAB, Attridge RL, Urteaga EM, Witte AP. An objective structured clinical examination to assess pharmacy resident performance. Innov Pharm. 2017;8(2):5.

29. Yardley S, Dornan T. Kirkpatrick's levels and education 'evidence'. Med Educ. 2012;46(1):97-106.

30. Saha S, Beach MC. The impact of patient-centered communication on patients' decision making and evaluations of physicians: a randomized study using video vignettes. Patient Educ Couns. 2011;84(3):386-92. 